\title{
THE DERIVATION OF ANAPHORIC RELATIONS BY GLYN HICKS
}

\author{
PAVEL RUDNEV \\ University of Groningen
}

Glyn Hicks' monograph sets out to answer some important questions facing any theory of anaphoric relations within contemporary generative linguistics: How are anaphoric relations to be understood given the current advances in Minimalist thinking? What is their nature? Do they have to be the black sheep of current generative grammar with their own stipulated domains, principles and operations? Or could they be restated derivationally, reducing to independently motivated ones? As the title suggests, the author opts for the derivational path.

The theoretical framework for the approach under scrutiny is a slightly modified version of Chomsky's Derivation by Phase (Chomsky 2001). In what follows I assume the reader's familiarity with fundamentals of this framework and, since the first two chapters review the history of anaphora in generative grammar, I follow Glyn Hicks' advice to proceed directly to outlining the gist of his idea starting with the end of chapter 2 .

Hicks proposes to modify Chomsky's version of the framework in at least two important respects: firstly, he agrees with Řežác (2004) that upwards probing has to be allowed; secondly, building on work by F.L. Marušič, O. Matushansky amongst others, he claims that phases come in two varieties, logical and phonological, with the former interpreting semanticosyntactic formal features and the latter morphosyntactic ones. I will return to both modifications shortly.

Hicks' general idea is that a derivational theory of binding is superior to one treating the constraints on binding as representational filters which apply at LF, and the arguments, both empirical and theoretical, in favour of the former occupy a significant part of the book (the whole of chapter 3, and occasionally in the later chapters). The reader should note that I do not intend to replicate all of the arguments but merely to give a taste of how the argumentation goes.

The main theoretical argument is keeping in spirit with the Minimalist Programme. Unlike many syntacticians who make use, implicitly or explicitly, of a version of a pre-minimalist Binding Theory, Hicks boldly embraces the theoretical challenge of getting rid of unwarranted assumptions and mechanisms such as binding domains and binding conditions that have previously been mostly stipulated. 
As for the empirical side of the debate on what type of binding theory is superior, Hicks demonstrates, quite successfully, to my mind, that a subset of data is better accounted for on the derivational view, and goes even further to argue that exactly those cases that have previously been deemed to constitute counterevidence for the derivational theories can actually be converted into arguments indirectly proving the derivational theories to be on the right track. Hicks examines four such 'counter-arguments': (i) trapping effects, i.e. configurations where an anaphor embedded in a displaced constituent is 'trapped' in a 'high' position for interpretive reasons; (ii) idiom interpretation; (iii) reconstruction with expletive associates, and (iv) reconstruction with bound pronouns. The idea is that the most successful attempts at explaining all four subsets of data make recourse to the notion of reconstruction which is assumed by most scholars to apply at LF. The approach Hicks takes in dealing with these problematic data pieces is show that they can be explained away independently of reconstruction.

Unlike some authors who argue for a non-reductionist derivationality in binding (cf. Bailyn Forthcoming), Hicks proposes that binding itself should be reduced to one of the two core operations, AGREE, with binding domains equated with phases in the sense of Chomsky 2001 (see also Hornstein 2000; Kayne 2002 for alternative views building on Move). On such a view no representational elements, such as binding conditions, are needed or desired. As AgreE operates on features, it has to be established which features it is that create the dependency.

After briefly considering several proposals as to how binding might be encoded syntactically (via $\varphi$-features or special referential features), the author dismisses them as inferior to the view that it is the operator and variable semanticosyntactic features of the sort proposed by Adger \& Ramchand (2005) that must be responsible for establishing the binding relation. Let us see how this system works.

Every anaphor entering the derivation carries an unvalued feature [VAR:_] which is, as the attribute suggests, semantically interpreted as a variable (1-b). This feature has to be valued before the current phase is completed with its content being rendered inaccessible to further syntactic operations; failure to do so will result in ungrammaticality due to the Phase Impenetrability Condition (2) leading to a violation of Full Interpretation (a constraint demanding that by Spell Out a derivation must have no unvalued features), as in (3). The valuation (1-c) is performed by a valued feature on the antecedent, thus establishing the desired syntactico-semantic dependency.
a. Every boy loves himself.
b. Every $[\mathrm{OP}: \forall],\left[\mathrm{VAR}_{\mathrm{A}: x]}\right.$ boy loves himself ${ }_{[\mathrm{VAR}:]}$
c. Every $[$ OP: $:]],[\mathrm{VAR}: x]$ boy loves himself ${ }_{[\mathrm{VAR}: x]}$
d. $\forall x \cdot \operatorname{boy}(x) \rightarrow \operatorname{love}(x, x)$ 
(2) Phase Impenetrability Condition (PIC)

"In phase $\alpha$ with head $\mathrm{H}$, the domain of $\mathrm{H}$ is not accessible to operations outside $\alpha$, only $\mathrm{H}$ and its edge [its specifier(s)] are accessible to such operations."

(3) * $\left[\right.$ TP John $\left[{ }_{v \mathrm{P}}<\mathrm{John}>\right.$ said $\left[\mathrm{CP}\right.$ that Mary $\left[{ }_{v \mathrm{P}}<\right.$ Mary $>$ likes himself $\left.\left.\left.]\right]\right]\right]$

We can see that (3) is a PIC violation because at the point when the higher phasal head is merged, the anaphor with unvalued features is trapped inside the lower phase $(v \mathrm{P})$, and the derivation crashes.

Considering (1-a), it becomes clear precisely why Hicks argues for upwards probing to be allowed, contrary to the more widely spread view that generally probes have to be higher in the structure than goals (see Adger 2010 for an attempt to derive this requirement): AGREE is triggered by the probe, which enters the derivation before the goal, and having found no matching valued feature in its c-command domain, it is forced to probe upwards as the last resort.

Trying to be semantically conscious, Hicks discusses the importance of discriminating binding from coreference (Reinhart 1983; Heim \& Kratzer 1998; Büring 2005, amongst others). I fear, however, that conceiving of anaphoric relations as occurring between an antecedent and a pronoun runs into a problem of encoding semantic binding by referential antecedents since there is no operator to bind the variable. Hicks counters this objection by hypothesising that once all necessary structural conditions for semantic binding are satisfied, a $\lambda$-operator is inserted below the antecedent at LF. I believe, however, that there are several reasons to think that this line of reasoning is flawed.

Firstly, such a move will force the interpretational interface to perform a syntactic operation, which Minimalism simply does not allow - the interfaces are merely allowed to impose very general constraints that will decide the fate of the derivation. Secondly, this step will create difficulties for the cases of VP-ellipsis since the required parallelism of the conjoined verb phrases is lost. Thirdly, this step runs contrary to the well-established intuition that binding is preferred over coreference - since we know that locally bound anaphors are interpreted as bound variables, it seems undesirable to introduce an additional operation at LF to deal with semantic binding of anaphors by referential antecedents. Next, given the strictly compositional interpretation that the minimalist framework demands, relegating interpretational tasks to the syntax/CI-interface rather than inserting a lambda-abstractor looks more theoretically parsimonious. Finally, another way to look at it is that on such a view, binding, in some well-defined sense, is performed via separate strategies depending on the type of the antecedent DP either by a quantifier or by a $\lambda$-operator occupying different syntactic positions. A widely held view is that the only elements capable of establishing (semantic) binding dependencies are $\lambda$-operators created by movement (see Elbourne 2005 
for an explicit proposal based on the theory of Heim \& Kratzer 1998).

A promising alternative would be to situate the operator features on phase heads thus retaining Adger \& Ramchand's original intuition that syntactic dependencies, including AGREE, are subject to locality constraints (cf. Adger 2008; Kratzer 2009) whilst also ensuring that both the elided and antecedent VPs are identical not only semantically, but also syntactically, thus keeping the semantic side of the story significantly more minimalist by not introducing any syntactic operations outside of narrow syntax (cf. Ramchand \& Svenonius 2008).

Needless to say that with traditional lexical entries in (4) and straightforward semantic composition followed by $\lambda$-conversion, the final semantic representations of (1) will be truth conditionally equivalent but the binding dependency will have been created lower in the structure, viz. before the merger of the antecedent thus ensuring predicate identity:

(4) a. $\quad \llbracket$ every boy $\rrbracket=\lambda P \cdot \forall y \cdot \operatorname{boy}(y) \rightarrow P(y)$

b. $\quad \llbracket$ love $\rrbracket=\lambda x . \lambda z . z$ loves $x$

(5) Every boy loves himself.

a. $\forall x \cdot \operatorname{boy}(x) \rightarrow \operatorname{loves}(x, x)$

b. Every boy $\lambda x$.love $(x, x)$

$=\lambda P[\forall y \cdot \operatorname{boy}(y) \rightarrow P(y)](\lambda x \cdot \operatorname{love}(x, x))$

$=\forall y \cdot \operatorname{boy}(y) \rightarrow(\lambda x \cdot \operatorname{love}(x, x))(y)$

$=\forall y \cdot \operatorname{boy}(y) \rightarrow \operatorname{love}(y, y)$

Another issue that Hicks pays much attention to in his book is that of noncomplementarity between anaphors and pronominals in the so-called snake-PPs (6) and picture-DPs (7).

(6) a. $\operatorname{John}_{i}$ saw a snake near himself . $_{i}$

b. $\mathrm{John}_{i}$ saw a snake near $\operatorname{him}_{i}$.

(7) a. A picture of himself seems to John $_{i}$ to be fake.

b. A picture ${ }_{i}$ of him seems to $\mathrm{John}_{i}$ to be fake.

Despite being very minimalist in nature, the author's solution differs very little from the existing analyses in that it relies heavily on the premise that the anaphor in such non-complementary positions is not a real anaphor but a logophor entering the derivation with a valued [VAR] feature (cf. Sells 1987; Reinhart \& Reuland 1993). In fact, on the current view, this move helps explain the behaviour of long-distance reflexives in, say, Scandinavian languages - an issue that I will discuss below; it does not, at least not straightforwardly, explain what it is that brings about the subtle semantic differences between the two pronominal forms that could be found in the literature. 
It would be particularly interesting to compare this solution with the approach to spatial anaphora of Rooryck \& Wyngaerd (2007) which claims to predict the subtle but systematic differences in meaning between the snake-sentences containing anaphors and those containing pronominals. The authors make use of the notion of axial parts, and propose that the relevant domains for pronominals and self-anaphors are established configurationally in a dynamic manner, as the derivation proceeds, which is quite in the spirit of Hicks' theory. The crucial difference would be that whilst Hicks treats anaphors in such environments as logophors, Rooryck \& Vanden Wyngaerd are sceptical of whether such a move is desirable.

We see that the approach to longer-distance anaphora advocated in Hicks' book, whereby such anaphors are given the feature specifications of pronominals, suffers from precisely those problems that have repeatedly been raised by the opponents of a generative binding theory. To exemplify, let us look at at least two of them. The first objection is theoretical in character. Huang (2000) claims, for instance, that the notion of logophoricity of Sells (1987) and Reinhart \& Reuland (1993) makes the reasoning circular and the theory unfalsifiable. The other objection is typological: it seems reasonable to ask the question why these logophors, whilst being rather different from African logophors and arguably rather similar to pronominals, look exactly like reflexives.

That said, let us return to the Binding Conditions. With Condition A reduced to feature valuation by AGREE, let us see what Hicks proposes to do about Condition $\mathrm{B}$, which is to reduce it to a violation of economy with the binding domain again being a phase.

It is here that the aforementioned distinction between PF and LF phases comes into play. Hicks builds on a number of famous examples to show that pronominals, unlike anaphors, are sensitive to certain phonological factors such as focal stress (contrast (8) with (9)), their binding domain must be the phonological phase. Following Epstein \& Seely $(2002 a, b)$ as well as several other authors, he assumes that morphosyntactic features, such as Case features, are interpreted by the PF-interface with semantico-syntactic features being interpreted by the LFinterface.

(8) a. John 1 read books about himself 1 .

b. ${ }^{*} \mathrm{John}_{1}$ read books about him 1 .

c. ${ }^{*} \mathrm{John}_{1}$ read books about ' $\mathrm{im}_{1}$.

d. John 1 read books about $\mathrm{HIM}_{1}$.

(Fiengo \& Higginbotham 1981)

(9) a. $\mathrm{John}_{i}$ read [DP books about 'imself ${ }_{i}$ ]

b. $\mathrm{John}_{i}$ read [DP books about himself $\left.{ }_{i}\right]$

c. $\operatorname{John}_{i} \operatorname{read}\left[\mathrm{DP}\right.$ books about $\left.\operatorname{~imSELF}_{i}\right]$ 


\section{d. $\operatorname{John}_{i}$ read $\left[\mathrm{DP}_{\text {books about himSELF }}\right.$ ]}

(Fiengo \& Higginbotham 1981)

The paradigm in (8) demonstrates that the ungrammaticality of pronominals in picture-DPs largely depends on prosodic, phonological factors: in particular, a prominent accent on him in (8-c) licenses the use of this pronominal whereas the very same sentence is ungrammatical when the pronoun is destressed. As (9) illustrates, anaphors are largely insensitive to phonological factors, and Hicks takes the contrast between (8) and (9) to speak volumes in favour of (i) discriminating between LF- and PF-phases, and (ii) different types of phases constituting binding domains for different types of pronouns.

It is easy to see the intuition that Hicks employs is a plausible one; however, the situation here is far more complicated. I can see at least two reasons, again empirical and theoretical, why caution has to be exercised when making a choice. Adger \& Ramchand (2005) argue that it is precisely the semantico-syntactic operator feature, their $[\Lambda]$ feature, that is responsible for determining the resultant phonological shape of the complementiser in Scottish Gaelic ${ }^{1}(10)$. This indicates quite the opposite of what Hicks assumes to be true, namely that semanticosyntactic features, at least some, are interpretable by PF. Another example is $\varphi$ features that have been argued to be essentially morphosemantic, see Harbour (2007) for a morphosemantic analysis of number. As for morphosyntactic features, they too cannot be completely invisible for LF but could rather be interpreted as (partial) identity functions.
a. an duine a thuirt e a bhuaileas e pro.
the man COMP said he COMP will.hit-REL he 'the man that he said he will hit'
b. *an duine a thuirte gum buaileadhe pro.
the man COMP-REL said he that would.hit he
'the man that he said he would hit'

Adger \& Ramchand $(2001,2005)$ analyse the difference between the two complementisers above, $a$ and $g u(n)$, as following from their different feature specifications with the former containing a $[\Lambda]$ feature and the latter lacking it. Rather than repeating the analysis I refer the interested reader to the relevant articles.

My theoretical concern is the implications that Hicks' theory makes as to the nature of abstract features and the two interfaces. Assuming that both morphosyntactic and semantico-syntactic features are attribute-value pairs, a fairly standard assumption indeed, it is not easy to see what it is that makes them different with respect to what interface they are 'visible' to. Put differently, one

[1] I thank David Adger (pc) for alerting me to this curious fact. 
might wonder whether the distinction is part of a feature's definition, whatever this might be, or whether the interfaces are 'programmed' in such a way as to interpret only a subset of all abstract features. Besides, such a classification risks making the resulting ontology suspiciously rich. I do not have my own solution to the problem but the issue is worth thinking over. What is clear, however, is that more research is necessary to derive the observed connection between phases and features in such a way as to avoid stipulation or circularity.

Let us proceed to examine the feature specifications that Hicks claims pronominals to have: as expected, they enter the derivation with valued [VAR], and upon completion of the PF phase the relevant features (e.g. Case features) are transferred to spellout. Hicks concedes that reducing Condition B to an application of AgreE is impossible, and, building on the work of B. Citko (Citko 2006), postulates an economy principle, Maximise Featural Economy (11).

Maximise Featural Economy (Hicks 2009: 204)

Establish dependencies via syntactic operations where possible

The above mechanism, which Hicks incorporates into the operation of AGREE itself, dictates that if a dependency (in our case, binding) can in principle be established syntactically, it has to be so established. This proposal depends crucially on the assumption that economy is not to be evaluated given a number of distinct numerations: the numerations under scrutiny have to be identical (contra Fox 2000; Reinhart 2006).

To see how this principle works, consider (12) below.

$$
\begin{aligned}
& \text { a. }{ }^{*} \mathrm{John}_{i} \text { loves himi }
\end{aligned}
$$

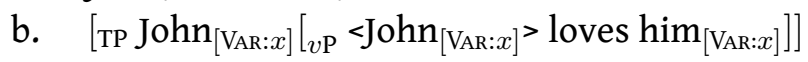

In (12) both the pronoun and its antecedent enter the derivation carrying a valued variable feature, yet the derivation is blocked by (11), since potentially (provided the pronoun's [VAR] were unvalued) the dependency could have been established by AGREE. In addition to being very elegant, this economy condition works very well with respect to the data from English. However, one would like to know more about the explanatory power of this priniciple when confronted with crosslinguistic evidence.

Having considered the way Hicks proposes to derive Conditions A and B, let us now proceed to examine how his approach deals with crosslinguistic evidence. Chapter 6, where the analysis is extended to deal with anaphora in three Germanic languages, Dutch, Norwegian and Icelandic, is in this sense extremely illuminating.

I fully agree with Hicks' view of the three driving forces of crosslinguistic variation when it comes to pronominal systems: (i) different feature specification of 
different anaphoric elements; (ii) additional syntactic properties of the pronoun in question; (iii) general syntactic characteristics of the language under examination (Hicks 2009: 218). Let us briefly discuss each of these.

As far as the feature specifications of pronouns in Dutch, Norwegian and Icelandic are concerned, these three languages possess anaphoric systems that are somewhat more complex than the English one. Since the three languages in question all have long-distance reflexives as well as locally bound ones, one has to be able to account for their distribution. Following earlier work on the topic, Hicks dubs the two types of reflexive SE and SELF reflexives. The latter pronouns are identical in their featural makeup to the English reflexives (i.e. they carry an unvalued [VAR:_]) whilst the same feature is valued on the former type. SE reflexives also have an additional privative feature [REFLEXIVE] which is semantically interpreted as reflexivising the predicate, very much in the spirit of Reinhart \& Reuland (1993). Curiously, the long-distance instances of SE reflexives differ substantially from non-locally bound reflexives in English: the former are reflexivising in nature whereas the latter are essentially emphatic or contrastive.

Now, as for the special syntactic properties of the pronoun in question, Hicks draws our attention to a number of them, of which I would like to single out just two: the absence of a structural Case feature on certain pronouns in Frisian can explain why these pronouns with local antecedents do not induce Condition B effects. Similarly, in Icelandic nominative objects are not subject to Condition B.

To illustrate his third point, Hicks gives evidence of a connection between $v \mathrm{P}$ like infinitival complements in Norwegian or Dutch on the one hand and covert head movement of SE reflexives in these languages to the relevant predicate resulting in an extension of the binding domain due to the deficient phasal status of such complements.

Generally, treating 'logophors' and long-distance reflexives in English and other languages as pronominals is quite customary; however, one must not forget that there are clear parallels between local and long-distance reflexives, as well as true logophors, with respect to their semantic interpretation (viz., strong preference for de se readings in intensional contexts). Also, more syntactic and semantic arguments helping to tease local binding from non-local binding of the sort discussed in Chapter 4 of the book, would have made the argumentation of this part of the book more convincing.

Be that as it may, some features of the tentative analyses of both local and long-distance binding that Hicks elaborates for Dutch, Norwegian and Icelandic crucially exploit, as does the analysis proposed for English, the split in phases into logical and phonological which I have discussed above. Until that question has been discussed and a reasonable concensus reached on what phases actually are, many of the design decisions remain largely theory-internal.

There is no doubt that Hicks' monograph presents an extremely valuable con- 
tribution to adapting the GB-era binding theory to the theoretical apparatus of the Minimalist Programme. A very important achievement is the explicit and elegant formulation of the binding operation as an application of AGREE. I also hope to have demonstrated that the book is positively thought-provoking in that it highlights the most burning issues in current theorising (e.g. motivation for phases, nature of the Phase Impenetrability Condition, formal feature classification and the structure of abstract features as well as constraints on Merge and AgreE all of them exciting but reasonably understudied questions) thus delimiting the domain for future research. There is no doubt that the book's pluses outweigh its minuses resulting in a novel and at the same time quite conservative view of the architecture of the language faculty in general and the nature of anaphoric relations in particular.

\section{REFERENCES}

Adger, David. 2008. Bare resumptives. In Proceedings of Resumptives at the Interfaces, lingBuzz/000709.

Adger, David. 2010. A Minimalist Theory of Feature Structure. In Anna Kibort \& Greville G. Corbett (eds.), Features: Perspectives on a key notion in linguistics, Oxford University Press.

Adger, David \& Gillian Ramchand. 2001. Phases and Interpretability. In Proceedings of wccfl 20 , .

Adger, David \& Gillian Ramchand. 2005. Merge and move: Wh-dependencies revisited. Linguistic Inquiry 36(2). 161-193.

Bailyn, John. Forthcoming. Kinds of Derivational Binding. In Proceedings of FDSL 7.5, .

Büring, Daniel. 2005. The syntax and semantics of binding theory. Cambridge University Press.

Chomsky, Noam. 2001. Derivation by phase. In Michael Kenstowicz (ed.), Ken Hale: A life in linguistics, 1-52. Cambridge, Massachusetts: MIT Press.

Citko, Barbara. 2006. The interaction between Across-the-Board wh-movement and left-branch extraction. Syntax 9(3). 225-247.

Elbourne, Paul D. 2005. Situations and individuals. MIT Press.

Epstein, Samuel David \& T. Daniel Seely. 2002a. Introduction: On the quest for explanation. In Samuel David Epstein \& T. Daniel Seely (eds.), Derivation and explanation in the minimalist program, 1-10. Malden, Massachusetts: Blackwell Publishing. 
Epstein, Samuel David \& T. Daniel Seely. 2002b. Rule applications as cycles in a level-free syntax. In Samuel David Epstein \& T. Daniel Seely (eds.), Derivation and explanation in the minimalist program, 65-89. Malden, Massachusetts: Blackwell Publishing.

Fiengo, Robert \& James Higginbotham. 1981. Opacity in NP. Linguistic Analysis 7(4). 395-421.

Fox, Danny. 2000. Economy and semantic interpretation. Cambridge, Massachusetts: MIT Press.

Harbour, Daniel. 2007. Morphosemantic number: From Kiowa noun classes to UG number features. Dordrecht: Springer.

Heim, Irene \& Angelika Kratzer. 1998. Semantics in generative grammar. Malden, MA: Blackwell.

Hicks, Glyn. 2009. The Derivation of Anaphoric Relations Linguistik Aktuell. Amsterdam: John Benjamins.

Hornstein, Norbert. 2000. Move! A Minimalist Theory of Construal. Oxford: Blackwell.

Huang, Yan. 2000. Anaphora. A cross-linguistic study. Oxford University Press.

Kayne, Richard S. 2002. Pronouns and their antecedents. In Samuel David Epstein \& Daniel Seely (eds.), Derivation and explanation in the minimalist program, 133-166. Blackwell.

Kratzer, Angelika. 2009. Making a Pronoun: Fake Indexicals as Windows into the Properties of Pronouns. Linguistic Inquiry 40(2). 187-237.

Ramchand, Gillian \& Peter Svenonius. 2008. Mapping a Parochial Lexicon onto a universal semantics. In M.T. Biberauer (ed.), The Limits of Syntactic Variation, 219-245. Amsterdam: John Benjamins.

Reinhart, Tanya. 1983. Anaphora and semantic interpretation. Chicago, Illinois: University of Chicago Press.

Reinhart, Tanya. 2006. Interface strategies. MIT Press.

Reinhart, Tanya \& Eric Reuland. 1993. Reflexivity. Linguistic Inquiry 24(4). 657-720.

Rooryck, Johan \& Guido Vanden Wyngaerd. 2007. The Syntax of Spatial Anaphora. In Monika Bašić, Marina Pantcheva, Minjeong Son \& Peter Svenonius (eds.), Tromsø working papers on language and linguistics: Nordlyd, vol. 34 2, 33-85. CASTL. http://www.ub.uit.no/baser/nordlyd. 
Sells, Peter. 1987. Aspects of logophoricity. Linguistic Inquiry 18(3). 445-480.

Řežác, Milan. 2004. Elements of Cyclic Syntax: Agree and Merge: University of Toronto dissertation.

AUTHOR CONTACT INFORMATION

Pavel Rudnev

University of Groningen

Department of Linguistics

Oude Kijk In 't Jatstraat 26

NL-9712 EK Groningen

The Netherlands

p.rudnev@rug.nl 